Note

\title{
Reduction in Oxidation Index Value of Fish Oils Using Hydrophobic Nonporous
}

\section{Denser Membrane Process}

\author{
Atsushi MiYagi $^{1 *}$, Hiroshi NABETANI ${ }^{2}$ and Mitsutoshi NAKAJIMA ${ }^{3}$ \\ ${ }^{1}$ Chiba Industrial Technology Research Institute, 889 Kasoricho, Wakabaku, Chiba 264-0017, Japan \\ ${ }^{2}$ National Food Research Institute, National Agriculture and Food Research Organization, Tsukuba, Ibaraki 305-8642, Japan \\ ${ }^{3}$ Graduate School of Life and Environmental Sciences, University of Tsukuba, Tsukuba, Ibaraki 305-8572, Japan
}

Received January 6, 2009; Accepted February 12, 2009

Attempts were made to remove the oxidation products from fish oil with membrane process as an improved refining method. A study was conducted with hexane-diluted fish oils of Engraulis japonicus and Maurolicus japonicus in a batch membrane cell using hydrophobic nonporous denser membrane. Peroxide, anisidine and TOTOX values were reduced by 58-72\%, 45-75\% and 53-73\%, respectively. During the membrane process, fatty acids compositions of both fish oils were not changed. The membrane process has an effect in the removal of oxidation products such as toxicity, off-flavor, and color compounds maintaining the beneficial function arising from polyunsaturated fatty acids of fish oils. In the fish oilhexane systems, when the oil contents of feeds were $25-33 \%$, the oil fluxes were obtained in the range of $1.0-2.0 \mathrm{~kg} /\left(\mathrm{m}^{2} \mathrm{~h}\right)$. In addition, preferential permeations of hexane over fish oils through the membrane were observed.

Keywords: fish oils, refining, membrane process, hydrophobic nonporous denser membrane, oxidation products, fatty acids composition, permeate flux

\section{Introduction}

Fish oils contain a large amount of polyunsaturated fatty acids (PUFA), which are not only essential for the development and function of the brain and retina (Lauritzen et al., 2001), but have also been implicated in having an effect on reducing specific risk factors for cardiovascular diseases and some types of cancer (Williams et al., 2006, Angerer et al., 2002). The prospect of using PUFA as potentially beneficial ingredients in foods presents an enormous opportunity to the fish oil industry and the food industry in general (Thomas et al., 1989). However, due to the high concentration of unsaturated fatty acids, fish oils are liable to form oxidation products that cause adverse effects (Viola and Bianchi, 1988) such as toxicity, off-flavor and browning of the oils. The undesirable oxidation products should be removed during refining and deodorization to obtain food grade oil.

The conventional refining process employs several unit steps, that is, degumming, alkali refining, bleaching, and vacu-

*To whom correspondence should be addressed.

E-mail: a.myg@mc.pref.chiba.lg.jp um deodorization (Karahadian and Lindsay, 1990). However, these processes have many drawbacks, such as a high energy requirement, the need for large amounts of water and chemicals, the need for equipment and disposal of highly polluted effluent. In the vacuum steam deodorization step, as a result of the high temperature $\left(190-230^{\circ} \mathrm{C}\right)$ required for fish oils, artifacts are formed through isomerization and polymerization reactions in fish oils (Karahadian and Lindsay, 1990). Moreover, fish oils are often hydrogenated to prevent the formation of oxidation compounds, such as the formulation of functional shortenings and margarines (Shibata and Shikayama, 1989). However, use of this method is considered problematic due to the production of trans fatty acids, which increases the risk to human health, such as the development of heart disease (Willet and Ascherio, 1994), as well as a loss of the beneficial functions attributable to PUFA. Therefore, a new refining technology, which maintains the fundamental properties of fish oils, is required.

Researchers are looking at membrane technology as an alternate process to the conventional refining of edible oils (Koseoglu and Engelgau, 1990, Snape and Nalajima, 1996). 
The membrane process is remarkably simple, offering many advantages over conventional processes, namely, low energy consumption, ambient temperature operation, and retention of nutrients and other desirable components (Koseoglu and Engelgau, 1990). Recently, a refining process of vegetable oils using a hydrophobic nonporous denser membrane has been created. Subramanian et al. (2004) reviewed that hydrophobic nonporous denser membrane was effective in removing phospholipids, color compounds and certain oxidation products of crude vegetable oils while preferentially permeating tocopherols. Our earlier studies on the processing of used frying oils using hydrophobic nonporous denser membrane showed that the quality of used frying oils could be improved, as was reflected in the reduction of total polar materials including polymers and color compounds (Miyagi et al., 2001).

In the present study, attempts were made to remove the oxidation products of fish oils, while maintaining their fundamental properties, by using the hydrophobic nonporous denser membrane as an improved refining method.

\section{Materials and Methods}

Fish oils Fish oils from Engraulis japonicus (offing of Chiba, Japan) and Maurolicus japonicus (offing of Shimane, Japan) were used in the experiments. The minced fish were freeze-dried, milled with a pestle, and extracted with diethyl ether. Diethyl ether in the extracted samples was removed in a rotary flash evaporator at $40^{\circ} \mathrm{C}$, with trace residuals removed by holding the samples in an evacuated desiccator at $60^{\circ} \mathrm{C}$ under vacuum $(<5 \mathrm{~mm} \mathrm{Hg}$ of absolute pressure). Solvent-free samples were used as fish oils (feeds). About $50 \mathrm{~g}$ of these samples were dispensed into bottles, flushed with nitrogen gas before sealing the bottles and stored in a freezer below $-30^{\circ} \mathrm{C}$. The frozen samples were thawed when required for use.

Membrane Hydrophobic nonporous denser membrane, NTGS-2200 (Nitto Denko Co. Ltd., Shiga, Japan), with silicon polymer as the active layer and polyimide as the support layer, was used in the experiments. The active layer thickness was approximately $3 \mu \mathrm{m}$. This membrane was originally developed for a gas-separation application, such as hexane vapor recovery in the petroleum industry.
Membrane batch experiment The apparatus with a selfstirred batch membrane cell (model C-70B; Nitto Denko Co. Ltd., Shiga, Japan) is shown in Fig. 1. Diameter and effective area of the membrane in the cell were $7.5 \mathrm{~cm}$ and $32 \mathrm{~cm}^{2}$, respectively.

In our previous study on the processing of used frying oils using hydrophobic nonporous denser membrane, we reported that the oil flux increased by 9- to 14-fold with hexane dilution of used frying oil as compared to the permeate flux obtained with undiluted oil (Miyagi et al., 2003). Therefore, the present study was also conducted with hexane diluted fish oils.

In order to estimate the effect of dilution hexane on oil flux, hexane-diluted feed samples for Engraulis japonicus and Maurolicus japonicus were prepared by dissolving $50.1 \mathrm{~g}$ and $50.5 \mathrm{~g}$ of oil in $102.4 \mathrm{~g}$ and $150.6 \mathrm{~g}$ of hexane, respectively (the oil contents of the feeds were 33\% for Engraulis japonicus and 25\% for Maurolicus japonicus, respectively). In all the experimental runs, temperature, operating pressure and speed of the spin bar were maintained at $25^{\circ} \mathrm{C}, 4 \mathrm{MPa}$ and $500 \mathrm{rpm}$, respectively. Experiments were stopped when the permeate collections for Engraulis japonicus and Maurolicus japonicus were $19.1 \mathrm{~g}$ and $23.3 \mathrm{~g}$ as oils, respectively. Hexane in permeates was removed using the same method as the fish oil preparation mentioned above. Solvent-free samples were used for analyses

Analyses Peroxide value (POV) and anisidine value (An.V) were determined using AOCS official methods $\mathrm{Cd} 8 \mathrm{~b}-90$ and Cd 18-90, respectively. TOTOX value was obtained by the following equation:

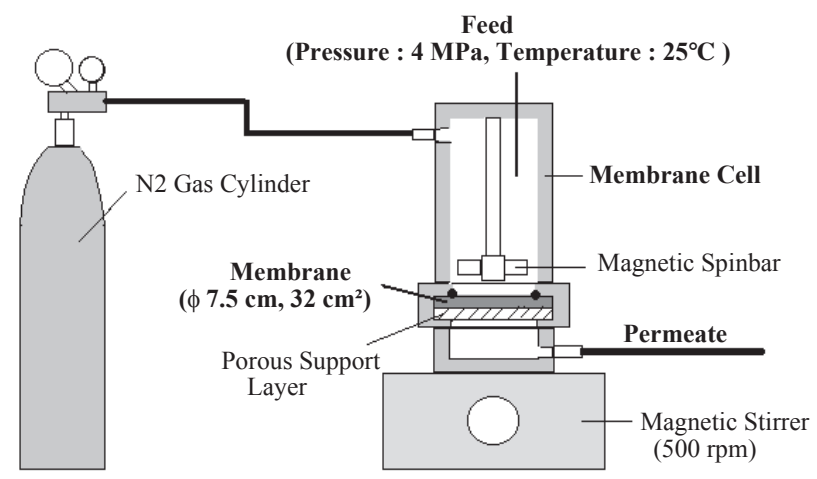

Fig. 1. Membrane Apparatus and Operating Conditions.

Table 1. Oxidation Products of Feed and Membrane-Processed Fish Oils.

\begin{tabular}{|c|c|c|c|c|c|c|}
\hline & \multirow{2}{*}{$\begin{array}{c}\mathrm{POV} \\
{[\mathrm{meq} / \mathrm{kg}]}\end{array}$} & \multirow{2}{*}{ An.V } & \multirow{2}{*}{ TOTOX } & \multicolumn{3}{|c|}{$P R[\%]$} \\
\hline & & & & POV & An.V & TOTOX \\
\hline \multicolumn{7}{|c|}{ Engraulis japonicus } \\
\hline Feed & $38.3 \pm 0.2$ & $43.4 \pm 0.7$ & $120.0 \pm 1.3$ & & & \\
\hline Permeate & $16.0 \pm 1.1$ & $23.9 \pm 0.3$ & $55.9 \pm 3.4$ & 58.2 & 44.9 & 53.4 \\
\hline \multicolumn{7}{|c|}{ Maurolicus japonicus } \\
\hline Feed & $43.8 \pm 1.1$ & $68.6 \pm 2.1$ & $156.2 \pm 4.3$ & & & \\
\hline Permeate & $12.3 \pm 0.9$ & $17.2 \pm 1.0$ & $41.8 \pm 1.6$ & 71.9 & 74.9 & 73.2 \\
\hline
\end{tabular}

POV: peroxide value, An.V: anisidine value

Mean value $\pm \operatorname{SD}(n=3)$ 


$$
\text { TOTOX }=2 \mathrm{POV}+\mathrm{An} . \mathrm{V}
$$

Fatty acid composition was determined with FID gas chromatography (AOCS Ce 1b-89) after the preparation of methyl esters of fatty acids (AOCS Ce 2-66).

Performance parameters The percent reduction, $P R \%$, was calculated using Equation 2,

$$
P R=100\left(C_{\mathrm{F}}-C_{\mathrm{p}}\right) / C_{\mathrm{F}}
$$

where, $C_{\mathrm{F}}$ and $C_{\mathrm{p}}$ are the contents of each component in the feed and the processed oils.

The oil flux, $J_{\mathrm{o}} \mathrm{kg} /\left(\mathrm{m}^{2} \mathrm{~h}\right)$ was calculated using Equation 3,

$$
J_{\mathrm{o}}=W_{\mathrm{o}} /(A t)
$$

where, $W_{\mathrm{o}}$ is the weight of the oil content in the permeate $(\mathrm{kg})$, $A$ is the effective area $\left(0.0032 \mathrm{~m}^{2}\right)$, and $t$ is the time taken for collecting the permeate $(\mathrm{h})$.

\section{Results and Discussion}

Removal of oxidation products The oxidation products of the feed and permeate are shown in Table 1. POV, An.V and TOTOX of feeds were $38 \mathrm{meq} / \mathrm{kg}, 43$ and 120 for Engraulis japonicus, and $44 \mathrm{meq} / \mathrm{kg}, 69$ and 156 for Maurolicus japonicus, respectively. During the membrane processes, POV, An.V and TOTOX were reduced by $58 \%, 45 \%$ and $53 \%$ for Engraulis japonicus, and $72 \%, 75 \%$ and $73 \%$ for Maurolicus japonicus, respectively.

Oxidation products such as peroxide, aldehydes, ketones, hydroperoxides, polymers and oxidized monomers can all cause harmful effects (Viola and Bianchi, 1988). POV is an indica- tor of peroxide and other similar oxidation products. Peroxide formation is, in particular, a major concern from a toxicological point of view. An.V measures the secondary oxidation products, namely the amount of aldehydes (AOCS, 1998). Thomas et al. (1989) reported that most of the volatile (off-flavor) components of fish oils were derived from oxidative degradation of PUFA, and a series of alkenals and alkadienals constituted the major volatile components. In addition, oxidation has an important effect on the color of oils. Oxidation results in the development of colored compounds, quinoid in nature, from the fatty acids or glycerides in the oils (Mounts and List, 1996). The TOTOX value is used as one of the parameters to evaluate the bleaching operation (Hodgson, 1996). POV in conjunction with An.V can be used to map the past and future degradation profiles. TOTOX is a useful value for quantifying oxygendirected oil degradation.

Due to the high reduction in oxidation products as mentioned above, the membrane process is useful for deodorization and decolorization, as well as reducing health risks.

As for the other refining process, in degumming and deacidification studies using crude vegetable oils and the hydrophobic nonporous denser membrane, it was reported that phospholipid contents were rejected by greater than 96\% (Subramanian and Nakajima, 1997), while free fatty acids permeated preferentially compared to triglycerides (Subramanian et al., 1998). From these results, the membrane process would have an effect on degumming, but no effect on deacidification.

Characterization of fatty acid composition Fatty acid compositions of the feed and permeate are shown in Table 2.

\begin{tabular}{|c|c|c|c|c|c|}
\hline & \multirow{2}{*}{$\begin{array}{c}\text { Fatty acids } \\
{[\mathrm{g} / 100 \mathrm{~g}-\text { total fatty acids }]}\end{array}$} & \multicolumn{2}{|c|}{ Engraulis japonicus } & \multicolumn{2}{|c|}{ Maurolicus japonicus } \\
\hline & & Feed & Permeate & Feed & Permeate \\
\hline $14: 0$ & Myristic acid & $7.7 \pm 0.02$ & $7.7 \pm 0.02$ & $5.3 \pm 0.03$ & $6.1 \pm 0.03$ \\
\hline $15: 0$ & Pentadecanoic acid & $0.6 \pm 0.03$ & $0.4 \pm 0.01$ & $0.7 \pm 0.04$ & $0.8 \pm 0.01$ \\
\hline $16: 0$ & Palmitic acid & $18.2 \pm 0.51$ & $18.3 \pm 0.01$ & $20.6 \pm 0.17$ & $21.1 \pm 0.05$ \\
\hline $16: 1$ & Palmitoleic acid & $7.2 \pm 0.10$ & $7.2 \pm 0.07$ & $6.6 \pm 0.02$ & $7.1 \pm 0.02$ \\
\hline $17: 0$ & Heptadecanoic acid & $1.5 \pm 0.15$ & $1.5 \pm 0.10$ & $1.9 \pm 0.06$ & $1.9 \pm 0.05$ \\
\hline $17: 1$ & Heptadecenoic acid & $1.2 \pm 0.03$ & $1.2 \pm 0.02$ & $1.5 \pm 0.03$ & $1.5 \pm 0.02$ \\
\hline $18: 0$ & Stearic acid & $4.3 \pm 0.07$ & $4.1 \pm 0.02$ & $3.0 \pm 0.03$ & $2.7 \pm 0.05$ \\
\hline $18: 1$ & Oleic acid & $10.5 \pm 0.09$ & $10.4 \pm 0.04$ & $20.0 \pm 0.17$ & $20.2 \pm 0.09$ \\
\hline $18: 2$ & Linoleic acid & $1.1 \pm 0.07$ & $1.2 \pm 0.05$ & $0.4 \pm 0.02$ & $0.5 \pm 0.01$ \\
\hline $18: 3$ & Linolenic acid & $2.2 \pm 0.05$ & $2.1 \pm 0.06$ & $1.8 \pm 0.08$ & $1.9 \pm 0.01$ \\
\hline $18: 4$ & Octadecatetraenoic acid & $5.2 \pm 0.02$ & $4.1 \pm 0.04$ & $5.1 \pm 0.07$ & $5.0 \pm 0.11$ \\
\hline $20: 0$ & Arachidic acid & $2.1 \pm 0.05$ & $2.1 \pm 0.03$ & $1.0 \pm 0.04$ & $1.1 \pm 0.08$ \\
\hline $20: 1$ & Icosenoic acid & $1.3 \pm 0.12$ & $1.5 \pm 0.02$ & - & - \\
\hline $20: 3$ & Icosatrienoic acid & $0.4 \pm 0.01$ & $0.5 \pm 0.02$ & - & - \\
\hline $20: 4$ & Arachidonic acid & $4.1 \pm 0.05$ & $3.6 \pm 0.03$ & $8.8 \pm 0.68$ & $8.1 \pm 0.83$ \\
\hline $20: 5$ & Eicosapentaenoic acid & $11.6 \pm 0.29$ & $12.3 \pm 0.03$ & $5.9 \pm 0.05$ & $6.2 \pm 0.27$ \\
\hline $22: 1$ & Docosenoic acid & $0.6 \pm 0.05$ & $0.6 \pm 0.06$ & $0.6 \pm 0.02$ & $0.6 \pm 0.05$ \\
\hline $22: 5$ & Docosapentaenoic acid & $2.4 \pm 0.16$ & $2.4 \pm 0.04$ & $3.3 \pm 0.06$ & $2.7 \pm 0.05$ \\
\hline $22: 6$ & Docosahexaenoic acid & $17.5 \pm 0.14$ & $18.9 \pm 0.16$ & $13.4 \pm 0.16$ & $12.5 \pm 0.43$ \\
\hline
\end{tabular}
Comparing fatty acid compositions of both fish oils, Engraulis

Table 2. Fatty Acid Contents of Feed and Membrane-Processed Fish Oils.

Mean value $\pm \operatorname{SD}(n=3)$ 
japonicus fish oil contained larger amounts of eicosapentaenoic (EPA) and docosahexaenoic acids (DHA), and Maurolicus japonicus fish oil contained larger amounts of oleic and arachidonic acids.

During the membrane process, presumably due to its mild condition, fatty acid compositions for both fish oils were unchanged, regardless of the high content (approximately 70\%) of unsaturated fatty acids. For example, EPA contents of feed and processed oil were $11.6 \%$ and $12.3 \%$ for Engraulis japonicus, respectively, DHA contents of feed and processed oil were 17.5\% and $18.9 \%$ for Engraulis japonicus, and arachidonic acid contents of feed and processed oil were $8.8 \%$ and $8.1 \%$ for Maurolicus japonicus. On the other hand, in conventional refining processes, elevated temperatures cause the formation of artifacts through isomerization and polymerization reactions in fish oils containing highly unsaturated fatty acids (Karahadian and Lindsay, 1990).

As mentioned above, the membrane process would have the potential to refine fish oils while maintaining the beneficial functionality arising from PUFA.

Permeability of fish oil-hexane system Permeate (oil) flux is an important factor in the membrane process as it has a direct bearing on process economics. Oil fluxes for Engraulis japonicus and Maurolicus japonicus were $1.99 \mathrm{~kg} /\left(\mathrm{m}^{2} \mathrm{~h}\right)$ and 1.04 $\mathrm{kg} /\left(\mathrm{m}^{2} \mathrm{~h}\right)$ when the oil contents of feeds were $33 \%$ and $25 \%$, respectively. This indicates that a suitable ratio of oil to oil-hexane feed to obtain the maximal oil flux exists. In our previous study on the used frying oil-hexane system, maximal oil flux was obtained when the oil content of feed was $47 \%$ in the process stream (Miyagi et al., 2003). In the present systems, if a plant with $10 \mathrm{~m}^{2}$ membrane area is used, about $250-480 \mathrm{~kg} / \mathrm{d}$ of fish oils can be processed.

In the present systems, the preferential permeation of hexane over fish oil through the membrane was also observed. For instance, in the Engraulis japonicus fish oil-hexane system, the oil contents of permeate and concentrate were $19 \%$ and $63 \%$, respectively. Subramanian et al. (2001) reported that the phenomenon could be mainly attributed to the synergistic effect of preferential sorption and concentration dependent solubility as well as diffusivity (according to the solution diffusion model).

Acknowledgement Dr. Moriyasu Murata provided valuable advice.

\section{References}

Angerer P., Kothny W., Stefan Störk S. and von Clemens S. (2002). Effect of dietary supplementation with $\omega-3$ fatty acids on progression of atherosclerosis in carotid arteries. Cardiovasc Res., 54, 183-190

AOCS (1998). Methods Cd 8b-90, Cd 18-90, Ce 1b-89 and Ce 2-66 in "Official methods and recommended practices of the American Oil Chemists' Society $5^{\text {th }}$ edn.” AOCS press, Champaign
Hodgson A.S. (1996). Refining and bleaching, in "Bailey's industrial oil and fat products, $5^{\text {th }}$ edn. Vol. 4" edited by Hui Y.H., John Wiley \& Sons Inc., New York, pp. 157-212

Karahadian C. and Lindsay R.C. (1990). Low temperature deodorizations of fish oils with volatile asidic and basic stream sources. $J$. Am. Oil Chem. Soc., 67, 85-91

Koseoglu S.S. and Engelgau D.E. (1990). Membrane applications research in the edible oil industry: an assessment. J. Am. Oil Chem. Soc., 67, 239-249

Lauritzen L., Hansen HS., Jorgensen MH., and Michaelsen KF. (2001). The essentiality of long chain n-3 fatty acids in relation to development and function of the brain and retina. Prog. Lipid Res., 40, 1-94

Miyagi A., Nakajima M., Nabetani H. and Subramanian R. (2001). Feasibility of recycling used frying oil using membrane process. Eur. J. Lipid Sci. Technol., 103, 208-215

Miyagi A., Subramanian R. and Nakajima M. (2003). Membrane and additional adsorption processes for quality improvement of used frying oils. J. Am. Oil Chem. Soc., 80, 927-932

Mounts T. and List G., (1996). Strage, stability and transport of fats and oils, in "Bailey's industrial oil and fat products, $5^{\text {th }}$ edn. Vol. 4" edited by Hui Y.H., John Wiley \& Sons Inc., New York, p. 414

Shibata T. and Shikayama M., (1989). Iwashinado jyuyougyosyuno shishitsu in "SougouShishitsukagaku" edited by Shikayama M., Kouseisyakouseikaku, Tokyo, pp. 831-844 (in Japanese)

Snape J.B. and Nakajima M. (1996). Processing of agricultural fats and oils using membrane technology. J. Food Eng., 30, 1-41

Subramanian R. and Nakajima M. (1997). Membrane degumming of crude soybean and rapeseed oils. J. Am. Oil Chem. Soc., 74, 971-975

Subramanian R., Nakajima M. and Kawakatsu T. (1998). Processing of vegetable oils using polymeric composite membranes. J. Food Eng., 38, $41-56$

Subramanian R., Raghavarao K.S.M.S., Nabetani H., Nakajima M., Kimura T. and Maekawa T. (2001). Differential permeation of oil constituents in nonporous denser polymeric membrane. J. Memb. Sci., 187, 57-69

Subramanian R., Nakajima M., Raghavarao K.S.M.S and Kimura T. (2004). Processing vegetable oils using nonporous denser polymeric composite membranes. J. Am. Oil Chem. Soc., 81, 313-322

Thomas C. Y.H., Stephen S.W., Warinda V. and Samuel P.M. (1989). Characterization of volatile components of menhaden fish (Brevoortia tyrannus) oil. J. Am. Oil Chem. Soc., 66, 114-117

Viola P. and Bianchi A. (1988). Clinical aspects of the frying of foods, in "Frying of food, principles, changes, new approaches" edited by Varela, Bender A.E. and Morton I.D., Ellis Horwood, Chichester, England, p. 129

Willet W.C. and Ascherio A. (1994). Trans fatty acids: are the effects only marginal? Am. J. Public Health, 84, 722-724

Williams CM., Burdge G. (2006). Long-chain n-3 PUFA: plant vs marine sources. Proc. Nutr. Soc., 65, 42-50. 